\title{
AÇÕES AFIRMATIVAS: QUEM SÃO OS DISCENTES DA PÓS- GRADUAÇÃO NO BRASIL?
}

\section{AFFIRMATIVE ACTIONS: WHO ARE THE GRADUATE STU- DENTS IN BRAZIL?}

DOI: http://dx.doi.org/10.5965/1984317815042019105

Fabiana Santos Pereira

Universidade Federal do Rio Grande do Sul

bianaseixas@gmail.com

Ivan Rocha Neto

Universidade Católica de Brasília

neto-ivan@hotmail.com

\begin{abstract}
RESUMO
Esta pesquisa reúne dados de estudos recentes sobre o perfil dos pós-graduandos no Brasil. Apesar da ausência de informações coletadas historicamente e de forma a abranger todos os cursos de mestrado e doutorado, as análises demonstram que mais de $70 \%$ dos estudantes deste nível de ensino são brancos. Em maio de 2016, o Ministério da Educação publicou a Portaria Normativa $n^{\circ} 13$, estabelecendo prazo para que as instituições federais de ensino superior apresentassem propostas de inclusão de negros (pretos e pardos), indígenas e pessoas com deficiência em seus programas de pós-graduação stricto sensu. A norma também delega à Coordenação de Aperfeiçoamento de Pessoal de Nível Superior (CAPES) a atribuição de coordenar a elaboração periódica do censo discente da pós-graduação brasileira, o que, conforme verificado no âmbito desta pesquisa, ainda não está previsto nas ações da instituição. Levantamento realizado com pró-reitores das instituições federais de ensino superior com cursos de mestrado e doutorado apontou que mais de $70 \%$ já adotam ações afirmativas em seus processos seletivos. No âmbito da pesquisa, foi proposto um módulo de preenchimento pelo próprio discente na Plataforma Sucupira para que a CAPES possa atender ao previsto na portaria e reunir informações oficiais sobre o perfil discente.
\end{abstract}

Palavras-chave: Ações afirmativas. Cotas. Discentes. Plataforma Sucupira. Pós-graduação.

\section{ABSTRACT}

This research was based on recent studies on the profile of graduate students in Brazil. Despite the absence of data collected officially and to cover all masters and doctoral courses, data shows that more than $70 \%$ of students at this level of education are white. In May 2016, the Ministry of Education published Normative Ordinance No. 13, establishing for federal higher education institutions to submit proposals for the inclusion of blacks, browns indigenous and people with disabilities in their graduate programs (masters and doctorate). The norm also goes to the Brazilian Federal Agency for Support and Evaluation of Graduate Education (CAPES), linked to the MEC, the attribution of coordinating the periodic preparation of the student census of the Brazilian graduate, what is not done yet. A survey conducted with pro-rectors of federal higher education institutions pointed out that more than $70 \%$ have already taken affirmative ac- 
tion in their selective processes. In the scope of the research, a module was filled out by the student himself on the Sucupira Platform so that CAPES can meet the provisions of Normative Rule 13 and also contribute to official information about the graduate student profile.

Keywords: Affirmative actions. Quotas. Graduate students.

\section{INTRODUÇÃO}

No dia 10 de maio de 2016, foi noticiado pela imprensa brasileira que a presidente da República do Brasil, Dilma Rousseff, anunciaria a edição de portaria de indução às ações afirmativas na pós-graduação stricto sensu. No dia seguinte, a Portaria Normativa MEC n 13, de 11 de maio de 2016, foi publicada pelo Ministério da Educação (MEC) no Diário Oficial da União. Na mesma data, o Senado Federal iniciou sessão para votar a abertura do processo de impeachment da Presidente da República. A sessão de mais de $20 \mathrm{~h}$ de duração encerrou no dia 12, com a aprovação da abertura do processo, o que resultou no afastamento temporário da presidente do cargo por 180 dias e em definitivo posteriormente. Michel Temer, como vice-presidente, assumiu, assim, o Governo Federal brasileiro. Encerra-se aí o governo que, reeleito em 2014, havia colocado como seu slogan o tema Pátria Educadora.

O que parecia uma sinalização de que a educação seria prioridade da segunda gestão, se esvaiu na turbulência política de apenas 16 meses de governo [...]. Talvez tenha sido uma tentativa de resgatar o que já estava se perdendo, os êxitos da área da educação da segunda gestão do presidente Luiz Inácio Lula da Silva e que se manteve durante o primeiro mandato de Dilma (PEREIRA; PORTO, 2017, p. 178).

Para esta pesquisa foram identificados alguns trabalhos que conseguiram traçar uma representação social dos estudantes de mestrado e doutorado brasileiros. Levantamento realizado em 2015, por um grupo de trabalho (GT) criado no âmbito do Ministério da Educação (MEC), utiliza dados do Instituto 
Brasileiro de Geografia e Estatística (IBGE) e apresenta o perfil racial da população brasileira: $47,7 \%$ de brancos, $50,7 \%$ de negros (pretos e pardos), 1,1\% de amarelos e 0,4\% de indígenas. Em suas conclusões (março/2016), o GT apontou para $70,86 \%$ de brancos, $27,08 \%$ de negros, $1,76 \%$ de amarelos e 0,31\% de indígenas na pós-graduação brasileira. Os números também revelam que $23,91 \%$ da população brasileira possui algum tipo de deficiência, dos quais a faixa etária de 15 a 64 anos concentra $24,90 \%$ das 45.606 .048 pessoas com deficiência. O grupo identificou que apenas 0,5\% dos estudantes analisados declararam algum tipo de deficiência, permitindo inferir que, de fato, existe uma falta de oportunidade e igualdade de ingresso para deficientes na pós-graduação. Além da evidência estatística, foi destacado no relatório1 que pouquíssimas instituições de ensino possuem ações inclusivas. Assim, destaca o GT, a necessidade imediata de que ações sejam realizadas pelo Governo Federal para criar processos de inclusão de estudantes autodeclarados negros, indígenas e com deficiência, transtornos globais do desenvolvimento e altas habilidades, em programas de mestrado, mestrado profissional e doutorado e em programas de mobilidade internacional.

A Portaria Normativa MEC $n^{\circ} 13$ foi editada no âmbito da Lei $n^{\circ}$ 12.288/2010, que instituiu o Estatuto da Igualdade Racial (BRASIL, 2010a); do Decreto $n^{\circ} 7.824 / 2012$ (BRASIL, 2012), que coloca em seu art. $5^{\circ}, \S 3^{\circ}$ que "as instituições federais de educação poderão, por meio de políticas específicas de ações afirmativas, instituir reservas de vagas suplementares ou de outra modalidade"; e do Supremo Tribunal Federal que declarou, em 2012, a Constitucionalidade das Políticas de Ações Afirmativas. A portaria estabeleceu prazo de 90 dias para que as instituições federais de ensino superior apresentassem propostas de inclusão de negros (pretos e pardos), indígenas e pessoas com deficiência em seus programas de pós-graduação stricto sensu (mestrado e doutorado). Algumas portarias para a área da educação foram publicadas nos dias

1 Estudo resultado do Grupo de Trabalho designado pela Portaria CAPES/MEC № 149 de 13 de novembro de 2015. 
finais do Governo de Dilma Rousseff, em 2016, tendo sido revogadas pela nova gestão. A Portaria Normativa $n^{\circ} 13$ está vigente.

\subsection{METODOLOGIA}

Realizamos, como previsto, uma pesquisa qualitativa (exploratória e descritiva) e incluímos também dados quantitativos. Iniciamos com a identificação da quantidade dos programas no âmbito do Sistema Nacional de Pós-Graduação (SNPG). Com extração realizada em agosto/2018, o Brasil possuía 4.453 PPG's, sendo 2.827 de instituições de ensino superior e pesquisa federais, que é o universo a ser tratado nesta pesquisa, pelo fato da Portaria Normativa $n^{\circ} 13 / 2016$ estar restrita às instituições federais.

Em março de 2017, foi solicitado para a Diretoria de Avaliação (DAV) da CAPES os e-mails das Pró-Reitorias de Pós-Graduação e Pesquisa cadastrados na Plataforma Sucupira2. Foi enviado um e-mail consultando se cada PPG daquela instituição já havia adotado ações afirmativas nos processos seletivos para discentes dos cursos de mestrado e doutorado. As respostas vieram por e-mail e foram classificadas em: 1- sim já adotaram ou 2- não adotaram. Esta coleta, como é possível identificar neste artigo, gerou a necessidade de um segundo levantamento a ser feito posteriormente.

Os estudos exploratórios foram consultados e identificados em instituições governamentais responsáveis pelo Censo Demográfico e pesquisas, assim como organizações não governamentais e privadas, que também realizam pesquisas com foco em temas sociais. Desses estudos, foram extraídos dados realacionados aos grupos focais de ações afirmativas, para embasamento qualitativo da motivação de ações voltadas à inclusão social em cursos de nível superior - em especial pós-graduação.

\footnotetext{
2 É ferramenta da CAPES para coletar informações, realizar análises e avaliações e ser a base de referência do Sistema Nacional de Pós-Graduação (SNPG). A Plataforma disponibiliza, em tempo real e com transparência, as informações, processos e procedimentos que a CAPES realiza no SNPG para toda a comunidade acadêmica. CAPES. Plataforma Sucupira. Disponível em: http://www.capes.gov.br/avaliacao/plataforma-sucupira. Acesso em 25 jan. 2019.
} 


\section{DESENVOLVIMENTO DA PESQUISA}

A expressão "ação afirmativa" surgiu nos Estados Unidos por meio do decreto 10.925/1961 (ESTADOS UNIDOS DA AMÉRICA,1961 apud SOWELL, 2016), assinado pelo presidente americano John F. Kennedy, demandando assegurar que os candidatos fossem empregados e que trabalhassem sem consideração de raça, cor, credo ou origem nacional (SOWELL, 2016). Para este estudo, consideram-se ações afirmativas para a pós-graduação o que prevê a Portaria Normativa do MEC $n^{\circ} 13 / 2016$, e para a graduação a Lei $n^{\circ}$ 12.711/2012 (BRASIL, 2012), que garante a reserva de $50 \%$ das matrículas por curso e turno nas universidades e institutos federais de educação, ciência e tecnologia a alunos oriundos integralmente do ensino médio público, em cursos regulares ou da educação de jovens e adultos. E o termo minorias como sendo grupos menos representados.

Ao abordar a pós-graduação, é importante contextualizar o universo da graduação. Dados recentes apontam que das 239.716 vagas de 130 instituições da rede federal de ensino superior ofertadas no primeiro semestre de 2018, 118.390 foram para ampla concorrência. Outras 103.940 atendem a Lei de Cotas e 17.386 são para ações afirmativas, totalizando 121.326 (BRASIL, 2018) vagas. Apesar do MEC separar as cotas das ações afirmativas, considera-se nesta análise a soma.

Passados seis anos da promulgação da Lei das Cotas no Brasil, o assunto ainda é polêmico. Para o ex-ministro da Educação, Renato Janine Ribeiro, em entrevista para esta pesquisa, é relevante que, ao se discutir reserva de vagas no ensino superior, se destaque alguns fatos: segundo ele, quando Luiz Inácio Lula da Silva assumiu a Presidência da República, em 2003, a rede federal de ensino superior contava com 100 mil vagas por ano. Hoje são 230 mil. Ele explica que, quando $50 \%$ dessas vagas são reservadas para as cotas, isso quer dizer que 115 mil vagas, todas elas novas, são destinadas a quem veio de escola pública, enquanto que as outras 115 mil vagas, das quais 15 mil novas, são dedicadas aos alunos que não se qualificam como potenciais cotistas. $\mathrm{A}$ 
ideia de que são passadas vagas de umas pessoas para outras não cabe, porque antigamente todo mundo disputava, mas somente uma minoria de egressos de escola pública, uma minoria de negros e de indígenas entravam na universidade. "Pode-se dizer que eram 100 mil vagas das quais talvez 90 mil, 80 mil fossem para o perfil de não cotistas. Esse perfil de não cotistas têm, hoje, 115 mil vagas", ressalta. Os números do SISU demonstram que a distribuição das vagas na graduação tornou-se uma política de inclusão social relevante e com visão estatal ultrapassando governos, até o momento. Mas, considerando o histórico de desigualdade de oportunidades na educação, é preciso expandir a análise para a pós-graduação que integra o ensino superior.

A CAPES, vinculada ao MEC, é o órgão responsável pela organização do Sistema Nacional de Pós-Graduação. Os dados são coletados anualmente pela Fundação, que recebe, via Plataforma Sucupira, as informações das coordenações dos Programas de Pós-Graduação de todo o País. Os dados dos discentes, no entanto, até 2016 estavam restritos a dados pessoais (nome, documento, e-mail), sexo, curso, área, situação (matriculado, titulado, bolsista ou não). Portanto, até aquele ano, dados socioeconômicos dos discentes não constam das informações oficiais do Governo Federal.

No Brasil, não há uma singularidade nacional no que diz respeito a características raciais ou classes sociais. Thomas Sowell afirma que um pleito ou suposição de singularidade nacional é uma das características mais comuns nos numerosos países, onde grupos preferenciais e cotas existem sob uma diversidade de nomes. Há, também, dificuldade dos promotores dessas políticas em assumir que elas devem ser de caráter permanente. "Pelo contrário, esforço considerável tem sido despendido para descrever tais políticas como 'temporárias' mesmo quando, de fato, elas insistam não só em permanecer, mas também em crescer." (SOWELL, 2016, p. 15).

Diferente de outros atos normativos, inclusive a Lei de Cotas, a Portaria Normativa $n^{\circ} 13$ não possui a característica da temporalidade. A esse respeito, Sowell afirma, "qualquer política 'temporária' cuja duração é definida pelo obje- 
tivo de conseguir alguma coisa que jamais foi alcançada antes em lugar algum do mundo, poderia ser mais adequadamente caracterizada como eterna." (SOWELL, 2016, p. 20). Pela Portaria Normativa no 13, a CAPES deve coordenar a elaboração periódica de censo discente da pós-graduação brasileira e o MEC monitorar as ações. Como ações de médio e longo prazo, os artigos $3^{\circ}$ e $4^{\circ}$, que tratam dessa coordenação e monitoramento das ações por parte dos dois órgãos, ainda não estão sendo cumpridos.

Em consulta ${ }^{3}$ presencial realizada à Diretoria de Avaliação da CAPES em setembro de 2017, sobre o censo discente previsto na portaria, obtivemos a informação de que não caberia à instituição realizar um censo. Segundo a diretora, outros órgãos do próprio Governo, com experiência neste tipo de coleta de dados, poderiam realizar tal tarefa. Posteriormente, no âmbito desse estudo, uma consulta foi realizada por e-mail, junto ao Gabinete da Presidência da CAPES, em 18 de novembro de 2017, oportunidade em que foram enviados os seguintes questionamentos: 1 - A CAPES, mesmo não tendo o papel de realizar um censo discente, tomará alguma providência para encomendar tal tarefa aos órgãos que poderiam fazê-lo, como o Instituto Nacional de Estudos e Pesquisas Educacionais Anísio Teixeira (Inep) ou IBGE? 2 - Se sim, é possível explicar o que está previsto? 3 - Se não, poderiam explicar os motivos? A resposta recebida foi: "A CAPES, por meio da sua Diretoria de Avaliação, dentro de suas atribuições, já introduziu na Plataforma Sucupira dois campos que visam coletar dados referentes a raça e necessidades especiais dos discentes da pós-graduação stricto sensu, conforme preconizado pela Portaria Normativa n¹3/2016 do Ministério da Educação (MEC). Dessa forma, ainda não há dados que possam ser levantados até a finalização do Coleta CAPES e a homologação das informações preenchidas no sistema."

Em consulta, via Serviço de Informação ao Cidadão (SIC) do MEC, sobre o previsto no Art. $4^{\circ}$ da portaria, o Ministério respondeu em 8 de janeiro de 2018: "Prezada Senhora, Em atenção à demanda encaminhada a este Ministé-

3 Diretora da pasta à época, Rita de Cássia Barradas Barata. 
rio por Vossa Senhoria questionando acerca da criação do grupo de trabalho previsto no artigo $4^{\circ}$ da Portaria Normativa MEC no 13 , de 11 de maio de 2016, que dispõe sobre a indução de Ações Afirmativas na Pós-Graduação, informamos o que se segue: No âmbito da temática tratada na Portaria Normativa MEC n 13, de 2016, destacamos que, conforme Ofício n 199/2017-DAV/CAPES, de 26 de dezembro de 2017, em resposta a solicitação de informações sobre censo discente da pós-graduação, previsto no art. $3^{\circ}$ da Portaria em questão, a CAPES enviou aos programas de pós-graduação stricto sensu o Ofício $n^{\circ}$ 1/2017-CGAP/DAV/CAPES, de 21 de novembro de 2017, por meio do qual, solicita aos programas o preenchimento dos campos Raça/Cor e Pessoas com Deficiência, acrescentados no módulo Coleta de Dados da Plataforma Sucupira. A Plataforma Sucupira é uma ferramenta de coleta de informações subsidiárias à realização de análises e avaliações dos programas de pós-graduação stricto sensu nacionais, sendo a base de referência do Sistema Nacional de Pós-Graduação (SNPG). O preenchimento dos campos citados passou a ser obrigatório a partir de 2017 para todos os discentes matriculado em pelo menos um mês deste ano, sendo necessária a atualização dos registros pelos programas. O preenchimento dos novos campos da Plataforma pelos programas, fornecerá uma base de dados consistente para o acompanhamento e monitoramento das ações afirmativas na pós-graduação, conforme previsto no art. $4^{\circ}$ da Portaria Normativa MEC no 13 , de 2016."

Fica evidente nas respostas dos órgãos que o SNPG carece ainda de dados sobre o perfil discente, e que o preenchimento dos campos Raça/Cor e Pessoas com Deficiência, acrescentados no módulo da Coleta de Dados da Plataforma Sucupira, para o exercício de 2017, contribuirá, mas não o suficiente para atender ao previsto na legislação.

Entre os estudos exploratórios sobre o perfil dos estudantes da pós-graduação stricto sensu, destaca-se o da Fundação Carlos Chagas (FCC), que publicou em 2015 relatório final da pesquisa "Desigualdades de cor/raça e sexo entre pessoas que frequentam e titulados na pós-graduação brasileira: 2000 e 
2010"4. Para a pesquisa, foram examinados dados sobre cor/raça, sexo e distribuição regional de pessoas que frequentam a pós-graduação. A literatura utilizada pelo grupo indica que as desigualdades de acesso, progressão e conclusão para as diferentes etapas da educação básica e do ensino superior são demarcadas pela cor/raça. Consta do relatório mencionado a seguinte afirmação:

As defasagens entre indicadores educacionais de negros e brancos estão presentes desde a primeira etapa do sistema educacional brasileiro e devem ser estudadas na interface com outros marcadores sociais como sexo, região de moradia, renda e faixa de idade. (FUNDAÇÃO CARLOS CHAGAS, 2015).

Ações afirmativas, cotas, políticas de acesso ao ensino superior, não constituem um tema novo. Na pós-graduação, porém, além da ausência de dados oficiais, as ações começaram a ser incluídas de forma pontual, há cerca de uma década, nas universidades públicas brasileiras, e o normativo federal foi publicado há pouco mais de dois anos. Defende-se neste trabalho que o tema, vinculado ao mais alto grau do ensino, precisa ser melhor explorado. Quando se aborda a necessidade de inclusão das minorias neste nível de ensino, afirmações como "nunca vi candidato ser reprovado em uma entrevista por ser negro ou deficiente" são comuns e têm como argumento central o denominado mérito acadêmico, como se a afirmação encerrasse o assunto, quando, na verdade, ignora que os motivos para a falta de estudantes na pós-graduação, oriundos das minorias existentes na nossa população, relaciona-se a uma série de fatores históricos, econômicos e sociais, como se atesta na afirmação abaiXO:

O mérito é um princípio do darwinismo social que estipula que 'na luta e na competição pela vida, são os melhores que ganham'. Quem são esses melhores em nossos exames de vestibular? Certamente, os alunos preparados nos bons colégios privados e nos melhores cursinhos do país. Mas nada confirma que são por natureza os mais inteligentes se os compararmos

$4 \mathrm{O}$ documento ressalta que as assimetrias por cor/raça e sexo na educação brasileira têm sido objeto de reflexão de vários autores nos últimos 30 anos e cita Hasenbalg (1979), Valle Silva e Hasembalg (2000), Henriques (2001), Beltrão e Teixeira (2004), Paixão (2010), Rosemberg e Madsen (2011). 
com aqueles alunos oriundos da escola pública, brancos e negros. (MUNANGA, 2013 apud MIRANDA; PRAXEDES; BRITO, 2016, p. 76).

Miranda, Praxedes e Brito alertam que não obstante a percepção do fato, cada vez mais evidenciado nas instituições brasileiras, de que a seleção para a pós-graduação tem início ao longo dos cursos de graduação a partir da inserção dos estudantes em grupos de pesquisa e projetos de iniciação científica financiados com recursos públicos, é possível compreender que o "mérito acadêmico" é, ao mesmo tempo, uma construção histórico-social e um dispositivo de hierarquização social e naturalização das desigualdades. (MIRANDA; PRAXEDES; BRITO, 2016, p. 77).

Esses dispositivos que, de certa forma, se materializam como naturalização das desigualdades, são exatamente o que precisam ser tratados, quando analisamos o perfil discente da pós-graduação.

Pesquisa divulgada pelo IBGE em 2017 aponta que, em 2016, a taxa de analfabetismo no país caiu para 7,2\%. Em 2015, 8\% dos brasileiros com 15 anos ou mais não sabiam ler ou escrever no País. O levantamento foi feito ao longo de 2016 por meio da Pesquisa Nacional por Amostra de Domicílios (PNAD). Naquele ano, o total de analfabetos foi estimado em 11,8 milhões de pessoas e "apresentou relação direta com a idade, aumentando à medida que a idade avançava, até atingir $20,4 \%$ entre as pessoas de 60 anos ou mais". Além de detectar que a taxa é maior entre os mais idosos, a pesquisa também aponta que o número é superior entre as pessoas pretas ou pardas. Se considerados apenas os autodeclarados brancos, a taxa total de analfabetismo é de $4,2 \%$, enquanto entre as que se declaravam pretas ou pardas o índice foi de $9,9 \%$. Em um recorte, que considera as pessoas com 60 anos ou mais, o percentual entre os dois grupos é de, respectivamente, $11,7 \%$ e $30,7 \%$. Essa relação foi constatada em todas as Grandes Regiões (AGÊNCIA IBGE NOTÍCIA, 2013). 


\section{Outro estudo (FÓRUM NACIONAL DE PREVENÇÃO E ERRADICAÇÃO} DO TRABALHO INFANTIL, 2019) denominado "Trabalho Infantil nos ODS [Objetivos de Desenvolvimento Sustentável (ODS), aprovados pelas Nações Unidas em 2015]", divulgado em outubro de 2017, aponta que crianças e adolescentes negras são as maiores vítimas, em números, do trabalho infantil no Brasil. Representam 62,7\% da mão de obra precoce no país. Quando se trata de trabalho infantil doméstico, esse índice aumenta para $73,5 \%$, sendo mais de $94 \%$ meninas.

Segundo dados da Anistia Internacional Brasil (ANISTIA INTERNACIONAL, 2018), em 2012, 56 mil pessoas foram assassinadas no Brasil. Destas, 30 mil são jovens entre 15 a 29 anos e, desse total, $77 \%$ são negros. A maioria dos homicídios é praticado por armas de fogo e menos de $8 \%$ dos casos chegam a ser julgados.

Com dados da graduação, Siems-Marcondes (2017) ressalta que, embora em termos percentuais a matrícula de estudantes com deficiência no ensino superior corresponda a apenas $0,42 \%$ do total de matriculados, segundo os dados do Censo Escolar do Inep, de 2014, esse número representa importante crescimento se comparado a 2004, quando esses estudantes correspondiam a apenas $0,12 \%$ do total de matriculados. Em números absolutos, no Brasil, em 2004, o país tinha 5.395 estudantes com deficiência matriculados no ensino superior, número que, em 2014 , chegou a 33.377 , crescimento de $518,66 \%$.

Poderiam ser listados diversos estudos e dados socioeconômicos que dão suporte à discussão proposta aqui. Florestan Fernandes em 1989 realizou um estudo com dados do censo de 1940 e descobriu que, a distribuição desigual das oportunidades vai das ocupações à educação e é tão forte, em termos relativos, em São Paulo quanto na Bahia. Em estudo posterior, a partir de dados mais recentes, Eduardo Matarazzo Suplicy constatou e concluiu de maneira similar: 
como é lenta a transformação das relações de classe que se cruzam com as relações de raça (FERNANDES, 2017, p. 40).

Especificamente sobre o protesto negro, Fernandes destaca que as duas expressões históricas mais significativas desse ativismo aparecem vinculadas com os movimentos sociais espontâneos que eclodiram, por exemplo, em São Paulo, na década de 1920 até meados de 1940, e o que surge em conexão com a consciência social de um racismo que, sem ser institucional (como nos EUA ou na África do Sul), provoca consequências igualmente devastadoras. Afirma o autor:

A questão de ser o racismo institucional ou camuflado possui menor importância do que ele representa na reprodução da desigualdade racial, da concentração racial da riqueza, da cultura e do poder, da submissão do negro como 'raça' à exploração econômica, à exclusão dos melhores empregos e dos melhores salários, das escolas. (FERNANDES, 2017, p. 56).

O número de estudantes negros (soma de pretos e pardos) no mestrado e no doutorado mais que duplicou de 2001 a 2013, passando de 48,5 mil para 112 mil, segundo dados da PNAD. Considerando apenas os estudantes pretos, o número passou de 6 mil para 18,8 mil, um aumento de mais de três vezes. Embora representem a maior parte da população $(52,9 \%)$, os estudantes negros representam apenas $28,9 \%$ do total de pós-graduandos. O número de estudantes brancos nessa etapa de ensino também aumentou nos últimos 12 anos, passando de 218,8 mil para 270,6 mil (EBC AGÊNCIA BRASIL, 2015).

As políticas de inclusão social para a educação dos últimos 15 anos podem resultar em mudanças no perfil dos que fazem pós-graduação, mas ainda não é possível afirmar que as fronteiras institucionais, em referência a Pierre Bourdieu, produzidas pela escola estejam superadas. Diogo Valença, ao apresentar em 2017 a reedição do livro de Florestan Fernandes, diz que mais de 50 anos depois das discussões da Lei Afonso Arinos (1951), primeira norma contra o racismo no Brasil, nos debates sobre as políticas de cotas e ações afirmativas, no caso o Estatuto da Igualdade Racial (BRASIL, 2010b); e a Lei $n^{\circ}$ 
10.639/03 (BRASIL, 2003); os mesmos dilemas raciais estavam sendo enfrentados no Brasil.

Pierre Bourdieu (2008) elaborou o diagrama "La distinction", representando o espaço social. Nele, os agentes são distribuídos na primeira dimensão, de acordo com o volume global de capital que possuem, e na segunda dimensão, de acordo com a estrutura de seu capital econômico e cultural. Para o autor, cada classe de posições corresponde a uma classe de habitus (ou de gostos) produzidos pelos condicionamentos sociais associados à condição correspondente e pela intermediação desses habitus e de suas capacidades geradoras, um conjunto sistemático de bens e de propriedades, vinculadas entre si por uma afinidade de estilo. Bourdieu, em discordância com o posicionamento de Marx sobre a existência de classes, defende a tese de "o que existe é um espaço social, um espaço de diferenças no qual as classes existem de algum modo em estado virtual, pontilhadas, não como um dado, mas como algo que se trata de fazer." (BOURDIEU, 2008, p. 27).

Bourdieu aborda os mecanismos que asseguram a reprodução do espaço social e do espaço simbólico. Para ele, esse modelo, que pode parecer muito abstrato, permite compreender o interesse crescente que as famílias, sobretudo as famílias privilegiadas e, entre elas, as famílias de intelectuais, de professores ou de membros das profissões liberais, dedicam à educação em todos os países avançados. Ele permite compreender também que as mais altas instituições escolares, aquelas que levam às mais altas posições sociais, sejam cada vez mais monopolizadas por crianças de categorias sociais privilegiadas, tanto no Japão quanto nos Estados Unidos ou na França. De maneira mais geral, permite compreender não apenas como as sociedades avançadas se perpetuam, mas também como elas mudam sob o efeito de contradições específicas do modo de reprodução escolar (BOURDIEU, 2008). Para o autor, a entrega de diplomas, frequentemente feita em cerimônias solenes, é comparável à sagração do cavaleiro. Afirma o autor:

Assim, no Japão, como na França, temos uma nobreza escolar hereditária de dirigentes de industrias, de grandes médicos, de 
altos funcionários e até de dirigentes políticos, e essa nobreza de escola comporta uma parte importante de herdeiros da antiga nobreza de sangue que reconverteram seus títulos nobiliárquicos em títulos escolares (BOURDIEU, 2008, p. 39).

As reflexões de Bourdieu vão ao encontro das análises derivadas da avaliação da realização de programas de formação acadêmica: "Equidade na Pós-graduação"5, criado para preparar grupos das minorias para concorrer a vagas em programas de pós-graduação. Entre os dados do perfil dos candidatos (público alvo), estão a comparação com a escolaridade dos pais. Apenas $6 \%$ dos pais dos candidatos e $8 \%$ das mães têm ensino superior completo6, sendo que $15 \%$ dos pais e $13 \%$ das mães nunca frequentaram o ensino formal (ARTE; UNBENHAUM; SILVÉRIO, 2016, p. 24). Em termos econômicos, a renda familiar média dos candidatos é de $R \$ 2.789,06$, com mediana de $R \$$ $2.324,50$ e desvio padrão de $\mathrm{R} \$ 1.926,65$. Os $25 \%$ mais pobres têm renda familiar média mensal de até $R \$ 1.500,00$, e os $25 \%$ mais ricos apresentam renda acima de $\mathrm{R} \$ 3.500,00$ (CUNHA, 2016, p. 25). De alguma maneira, a análise de Bourdieu explicita o que está por trás do problema educacional brasileiro:

O sistema de educação pode na verdade assegurar a perpetuação do privilégio unicamente pelo jogo de sua própria lógica; dito de outra forma, ele pode servir aos privilégios sem que os privilégios tenham que se servir dele: em seguida, toda reivindicação que tende a autonomizar um aspecto do sistema de ensino, ainda que se tratando do ensino superior na sua totalidade, ou, por abstração ao segundo grau, de um ou do outro aspecto do ensino superior, serve objetivamente ao sistema e a tudo o que serve ao superior para assegurar a perpetuação do privilégio social. [...]

\footnotetext{
5 Parceria do Escritório do Brasil da Fundação Ford e do Departamento de Pesquisas Educacionais da Fundação Carlos Chagas (FCC) publicado no livro: ARTE, Amélia; UNBENHAUM, Sandra; SILVÉRIO, Valter (Org.) Ações afirmativas no Brasil: experiências bem-sucedidas de acesso na pós-graduação. v. 1. São Paulo: Fundação Carlos Chagas, 2016.

$6 \mathrm{O}$ concurso foi lançado em 2011, contemplando 12 propostas 15 universidades, que entre os anos 2012 e 2014 realizaram cursos de orientação pré-acadêmica, oferecendo formação instrumental prioritariamente a estudantes egressos de experiências de ação afirmativas na graduação, sobretudo negros e indígenas, visando a sua preparação para o processo seletivo de PPG. Nesse período, os 12 cursos contabilizaram 2.326 candidatos, 1.197 alunos inscritos nos programas, em um total de 32 turmas, havendo notificação de 165 ex-alunos aprovados (ingressantes) em PPG.
} 
Enfim, a eficácia dos fatores sociais de desigualdade é tamanha que a igualização dos meios econômicos poderia ser realizada sem que o sistema universitário deixasse de consagrar as desigualdades pela transformação do privilégio social em dom ou em mérito individual. Ou melhor, realizada a igualdade formal das chances, a escola poderia pôr todas as aparências da legitimidade a serviço da legitimação dos privilégios. (BOURDIEU, PASSERON, 2015, p. 45).

Ao se tomar conhecimento das reivindicações de entidades da sociedade civil organizada para a questão das ações afirmativas para acesso aos cursos, como a Associação Nacional dos Pós-Graduandos (ANPG) (ANPG, 2018), é possível questionar se há resistência por parte dos gestores governamentais e da própria academia em implementar ações afirmativas na pós-graduação. Este estudo partiu da hipótese de que há sim resistência, dado que o discurso sobre o mérito acadêmico está sempre presente quando o assunto é o acesso a cursos de mestrado e doutorado.

\section{RESULTADOS}

A partir da hipótese de que existem resistências à implementação das ações afirmativas na pós-graduação, foi realizado um breve exercício para este estudo, estruturado na forma de uma consulta7. Uma questão foi enviada por email em março de 2017 às pró-reitorias de pós-graduação e pesquisa das 157 instituições federais, com programas recomendados pela CAPES ${ }^{8}$, e obtivemos 44 respostas. Dessas, 13 informaram não possuírem ações afirmativas e 31 informaram que sim ou que já tiveram seleção com cotas em alguns PPG ou em todos ou já aprovaram comissão ou resolução interna sobre o assunto. Neste universo, mais de $70 \%$ das instituições já possuem ações afirmativas realizadas nas seleções de discentes. Essas 44 instituições representam um total

\footnotetext{
${ }^{7}$ A questão enviada aos pró-reitores foi: "A Pró-reitoria de Pesquisa e Pós-Graduação de sua IES possui informações de quantos e quais PPG adotaram ações afirmativas nos processos seletivos de discentes? Se sim, poderiam repassar essas informações?"

8 Dados extraídos da Plataforma Sucupira.
} 
de 840 programas de pós-graduação em funcionamento (Plataforma Sucupira - outubro/2017).

Com dados de dezembro de 2017, o SNPG possui 4.844 PPG's em funcionamento. Os 840 PPG's (das 44 instituições que responderam o e-mail) representam $17,34 \%$ do total, o que é pouco representativo, tendo em vista que as instituições federais possuem mais de 2,6 mil cursos, totalizando $53,70 \%$ dos mestrados e doutorados em funcionamento no Brasil. A partir disso, considerou-se necessário um levantamento mais abrangente em nível de Programa de Pós-Graduação, o que também acarretou a proposição, apresentada ao final, de criação de um módulo específico para coleta de dados na Plataforma Sucupira, sob responsabilidade da CAPES.

Os dados coletados, apesar de incipientes, descontroem, inicialmente, a hipótese levantada de que há resistência em realizar ações afirmativas para acesso de negros (pretos e pardos), indígenas e deficientes. Sabendo que a portaria do MEC deixa a cargo das IES a implementação dessas ações, e que já foi identificado que não há um controle ou cobrança por parte da CAPES ou do MEC sobre a adoção dessas iniciativas, pode-se extrair desse exercício que, na verdade, há uma predisposição dos dirigentes das universidades em implementar essas políticas. No entanto, ressaltamos que a "nobreza escolar hereditária" que tomamos empretada de Bourdieu ainda é uma realidade no sistema educacional, em especial nos níveis mais avançados. Para que seja possível mudanças estruturais, na pós-graduação brasileira, é necessário que a comunidade acadêmica e os órgãos responsáveis pelas políticas se voltem para a Avaliação coordenada pela CAPES, pois esta é base para todas as ações no âmbito do SNPG - da autorização de cursos à volume de recursos investidos nos cursos e nas pesquisas.

A avaliação dos programas de pós-graduação da CAPES tem sido constantemente questionada pela própria comunidade acadêmica. É importante esclarecer que nas regras vigentes o peso de cada item avaliado é definido pelos membros das próprias 49 áreas do conhecimento (CAPES, 2018a). A CAPES, 
por meio de suas portarias, orienta todos os processos, mas as decisões são tomadas com base nas reuniões dos comitês de área, do Conselho TécnicoCientífico da Educação Superior (CTC-ES), do Conselho Superior e em diálogo constante com entidades representativas dos diversos segmentos da comunidade acadêmica, como o Fórum de Pró-Reitores de Pesquisa e Pós-Graduação (Foprop), a Associação Nacional dos Dirigentes das Instituições Federais de Ensino Superior (Andifes), Associação Nacional dos Pós-Graduandos (ANPG), entre outros. O modelo atual de avaliação da pós-graduação foi importante e reconhecido mundialmente, pois foi com esse modelo, criado no final da década de 1970 e aperfeiçoado nos anos 2000, que o país ficou entre os 15 maiores produtores de ciência no mundo. No entanto, o sistema cresceu e o atual modelo se demonstra saturado. É o que dizem os próprios gestores e acadêmicos (ver textos publicados no site oficial (CAPES, 2018b; 2018c).

O Plano Nacional de Pós-Graduação (PNPG 2011-2020), documento norteador deste nível de ensino no Brasil, e os relatórios da comissão de acompanhamento do plano de 2013, 2014, 2016-2017 (CAPES, 2018d) não abordam o perfil dos estudantes de mestrado e doutorado. A parte dedicada aos discentes trata especificamente dos matriculados e titulados por região geográfica e por área do conhecimento e suas projeções de crescimento dentro desses contextos. A ausência da abordagem social é significativa.

Outro grupo de trabalho criado pela CAPES em 2015 (CAPES, 2019) debruçou sobre os impactos sociais da pós-graduação. Em texto divulgado no site da instituição, a pró-reitora de pesquisa da Universidade Estadual Paulista (Unesp), Maria José Soares Mendes Giannini, apresentou alguns apontamentos do GT em reunião do Foprop em novembro de 2016, entre eles, o de que ainda não existe consenso acerca da definição de impacto social e que a análise desse impacto requer diferentes tipos de dados e fontes de informação. Quanto às questões debatidas no GT, relacionadas aos PPG's, a pró-reitora destacou a contribuição para a formação de recursos humanos e sua inserção no mercado de trabalho e/ou em atividades de aprimoramento e se houve am- 
pliação de grupos subrepresentados como, por exemplo, de gênero, etnias, pessoas com deficiência e assimetrias geográficas.

Tendo como base essas discussões brevemente citadas aqui, é possível reconhecer que, por um lado o país passou por um período de relevantes transformações no ensino superior brasileiro, e podemos citar a criação de novas universidades, expansão de campi das universidades federais pelo interior do país, por meio dos programas do MEC como o de Apoio a Planos de Reestruturação e Expansão das Universidades Federais (Reuni), Universidade para Todos (Prouni), reformulação do financiamento estudantil (FIES), todos com foco na expansão do acesso e inclusão das minorias na universidade. Esses programas, de uma maneira natural, possibilitam que a pós-graduação se torne mais acessível a (uma massa) amplos segmentos da sociedade brasileira que antes ficavam limitados ao ensino médio como o seu mais alto grau de escolaridade. Por outro lado, há entre os estudiosos do tema, consenso quanto aos desafios que precisam ser superados pelo ensino superior no Brasil (graduação e pós-graduação).

O GT criado pelo MEC em 2015 propôs em suas recomendações a aplicação de um questionário socioeconômico destinado aos discentes da pósgraduação, visando manter um sistema de dados estatísticos atualizado, com as informações socioeconômicas dos estudantes da pós-graduação. O grupo também propõe que a cada dois anos deve ser realizada avaliação dos processos de inclusão. Entende-se que essas propostas devem ser levadas em consideração, mesmo que necessitem de alguma adaptação. Como contribuição, apresenta-se neste trabalho uma nova proposta, que pode ser implementada a curto prazo e de forma objetiva, envolvendo o discente diretamente, e não apenas as coordenações dos programas. Propõe-se acrescentar um módulo na Plataforma Sucupira a ser preenchido pelo próprio discente de forma obrigatória para todos os matriculados. O módulo deveria ser aberto na metade do período entre duas avaliações quadrienais da CAPES, sendo a primeira ainda em 2019 ou no máximo em 2020. O preenchimento deveria ser realizado uma única vez por discente enquanto estudante de cada modalidade da pós-graduação 
(mestrado e doutorado). O módulo ficaria aberto entre os meses de junho a setembro, para contemplar os novos matriculados e os que estão por titular-se. $O$ questionário deveria abranger questões socioeconômicas e seriam de caráter declaratório. Com base nos dados coletados, a CAPES teria, a cada quatro anos, uma espécie de retrato dos discentes. Os resultados obtidos deveriam ser disponibilizados em dados abertos, atendendo ao Decreto $\mathrm{n}^{\circ}$ 8.777/2016 (BRASIL, 2016); e trabalhados para divulgação em formato de indicadores. Os PPG seriam os responsáveis por controlar a obrigatoriedade do preenchimento por parte do estudante, como uma das tarefas do aluno matriculado.

Também se considera necessário que seja inserido no Coleta CAPES, para preenchimento anual, por parte da coordenação dos PPG, informação sobre a implementação de ações afirmativas para acesso discente e quantos estudantes ingressam, a cada seleção, por essas ações. Entende-se que esse módulo proposto na Plataforma Sucupira, que se tornou o sistema de gestão para a Avaliação da Pós-Graduação, seja uma solução viável a ser implementada a curto prazo e que traria importante contribuição para as políticas voltadas à pós-graduação para os próximos anos.

\section{CONSIDERAÇÕES FINAIS}

Até o momento a CAPES e o MEC informaram que haverá coleta de informações via Plataforma Sucupira da raça e deficiência dos discentes, a ser informadas pela coordenação dos cursos, o que contempla parcialmente o que está previsto na Portaria Normativa MEC Nº 13.

Tendo como base os estudos exploratórios, que indicam que 70,86\% dos estudantes de mestrado e doutorado são brancos, e que $70 \%$ das instituições federais de ensino superior que responderam ao levantamento realizado nesta pesquisa já implementaram ações afirmativas para o acesso discente, conforme prevê a portaria, considera-se essencial a coleta sistemática de acompanhamento da adoção dessas ações e de análise de sua eficácia. Essa 
deve ser uma das prioridades neste momento em que a pós-graduação brasileira tem sido repensada.

O PNPG encerra o seu período em 2021. O país mudou consideravelmente sua representação social em todas as instâncias na última década e a instabilidade política tem trazido preocupações quanto à condução de ações voltadas à assuntos essenciais ao desenvolvimento humano e social. Esses dados trabalhados poderão subsidiar a elaboração e realização de políticas públicas para a pós-graduação com a abrangência que consideramos necessária.

Fica a recomendação à CAPES para que elabore e inclua o módulo proposto neste artigo no ano de 2019/2020, para que seja possível posteriormente trabalhar os dados possibilitando a obtenção de indicadores que auxiliem na formulação de adoção de políticas públicas com foco na inclusão social.

\section{REFERÊNCIAS}

AGÊNCIA IBGE NOTÍCIA. PNAD Contínua 2016: $51 \%$ da população com 25 anos ou mais do Brasil possuíam apenas o ensino fundamental completo. Disponível em: https://agenciadenoticias.ibge.gov.br/agencia-noticias/2013-agencia-de-noticias/releases/18992-pnad-continua-2016-51-da-populacao-com-25anos-ou-mais-do-brasil-possuiam-apenas-o-ensino-fundamental-completo.html. Acesso em 07 mar. 2018.

ANISTIA INTERNACIONAL. Jovem Negro Vivo: Dos 30.000 jovens vítimas de homicídios por ano, $77 \%$ são negros. Queremos ver os jovens vivos. Chega de homicídios! Disponível em: https://anistia.org.br/campanhas/jovemnegrovivo/. Acesso em 8 mar. 2018.

ANPG. Bandeira histórica da ANPG, as cotas na pós-graduação são hoje realidade. Disponível em: http://www.anpg.org.br/bandeira-historica-da-anpgas-cotas-na-pos-graduacao-sao-hoje-realidade/_. Acesso em 6 mar. 2018.

BOURDIEU, Pierre. Razões práticas: sobre a teoria da ação. 9. ed. Tradução de Mariza Correa. Campinas, SP: Papirus. 2008. 
BOURDIEU, Pierre; PASSERON, Jean-Claude. Os Herdeiros: os estudantes e a cultura. Tradução de Ione Ribeiro Valle e Nilton Valle. Florianópolis: Editora da UFSC, 2014.

BRASIL. Decreto $\mathbf{n}^{\circ} 7.824$ de 11 de out. 2012: Regulamenta a Lei no 12.711, de 29 de agosto de 2012, que dispõe sobre o ingresso nas universidades federais e nas instituições federais de ensino técnico de nível médio. Disponível em: http://www.planalto.gov.br/ccivil_03/_ato2011-2014/2012/Decreto/D7824.htm. Acesso em 12 fev. 2019.

BRASIL. Decreto $n^{\circ} 8.777$ de 11 de maio 2016. Institui a Política de Dados Abertos do Poder Executivo Federal. Brasília: Diário Oficial da União, 2016.

BRASIL. Lei n 10.639 de 09 de janeiro de 2003. Estabelece as diretrizes e bases da educação nacional, para incluir no currículo oficial da Rede de Ensino a obrigatoriedade da temática "História e Cultura Afro-Brasileira". Brasília: Diário Oficial da União, 2003.

BRASIL. Lei no 12.288 de 20 de julho de 2010. Institui o Estatuto da Igualdade Racial. Brasília: Diário Oficial da União, 2010a.

BRASIL. Lei $\mathrm{n}^{\circ}$ 12.288, de 20 de julho de 2010: Institui o Estatuto da Igualdade Racial; altera as Leis nos 7.716, de 5 de janeiro de 1989, 9.029, de 13 de abril de 1995, 7.347, de 24 de julho de 1985, e 10.778, de 24 de novembro de 2003. Brasília: Diário Oficial da União. 2010b.

BRASIL. Lei $n^{\circ} 12.711$ de 29 de ago. 2012: Dispõe sobre o ingresso nas universidades federais e nas instituições federais de ensino técnico de nível médio. Brasília, Diário Oficial da União, 2012.

BRASIL. Ministério da Educação. Sistema de Seleção Unificada - SISU 1/2018. Disponível em: http://portal.mec.gov.br/index.php?option=com_docman\&view=download\&alias $=82361-09-02-18$-sisu-2018-1-balancofinal\&category_slug=fevereiro-2018-pdf-2\&Itemid=30192. Acesso em: 06 mar. 2018.

CAPES. CAPES, Foprop e ANPG falam de avaliação e fomento da pósgraduação na SBPC. Disponível em: http://www.Capes.gov.br/sala-de-imprensa/noticias/8476-Capes-foprop-e-anpg-falam-de-avaliacao-e-fomento-da-posgraduacao-na-69-reuniao-anual-da-sbpc. Acesso em: 07 mar. 2018c.

CAPES. Plano Nacional de Pós-Graduação - PNPG 2011-2020. Disponíveis em: http://www.capes.gov.br/plano-nacional-de-pos-graduacao. Acesso em: 07 mar. 2018d. 
CAPES. Presidente da CAPES fala do orçamento e dos principais desafios da pós-graduação. Disponível em: http://www.Capes.gov.br/sala-de-imprensa/ noticias/8471-presidente-da-Capes-fala-do-orcamento-e-dos-principais-desafios-da-pos-graduacao. Acesso em: 07 mar. 2018b.

CAPES. Pró-reitora de pesquisa defende análise sobre egressos da pósgraduação. Disponível em: http://www.capes.gov.br/sala-de-imprensa/noticias/ 8171-pro-reitora-de-pesquisa-defende-analise-sobre-egressos-da-pos-graduacao. Acesso em: 12 mar. 2019.

CAPES. Tabela de áreas de conhecimento/avaliação. Disponível em: http:// www.capes.gov.br/avaliacao/instrumentos-de-apoio/tabela-de-areas-do-conhecimento-avaliacao. Acesso em 06 mar. 2018a.

CUNHA, Célio da (Coord.). O MEC pós-Constituição. Brasília: Líber Livro, 2016.

EBC AGÊNCIA BRASIL. Negros representam $28,9 \%$ dos alunos da pósgraduação: A universidade ainda é controlada pelos interesses dos brancos. Disponível em: http://agenciabrasil.ebc.com.br/educacao/noticia/2015-05/negros-representam-289-dos-alunos-da-pos-graduacao. Acesso em: 22 abr. 2018.

ESTADOS UNIDOS DA AMÉRICA. Decreto $n^{\circ}$ 10.925/1961. Demandando que a ação afirmativa assegurasse que os candidatos fossem empregados e que trabalhassem sem consideração de raça, cor, credo ou origem nacional. In: SOWELL, Thomas. Ação afirmativa ao redor do mundo. São Paulo, SP: Realizações, 2016.

FERNANDES, Florestan. Significado do protesto negro. São Paulo: Expressão Popular: Fundação Perseu Abramo, 2017.

FÓRUM NACIONAL DE PREVENÇÃO E ERRADICAÇÃO DO TRABALHO INFANTIL (FNPETI). Negros são maioria no trabalho infantil. Disponível em: http://www.fnpeti.org.br/noticia/1826-negros-sao-maioria-no-trabalho-infantil.html. Acesso em: 12 fev. 2019.

FUNDAÇÃO CARLOS CHAGAS. Desigualdades de cor/raça e sexo entre pessoas que frequentam e titulados na pós-graduação brasileira: 2000 e 2010. Disponível em: http://www.fcc.org.br/fcc/images/pesquisa/pdf/pesquisadesigualdades-de-cor-e-sexo.pdf. Brasília: FCC, 2015.

MUNANGA, 2013 apud MIRANDA, Shirley, PRAXEDES, Vanda Lucia, BRITO, José Eustáquio. Afirmação na Pós-Graduação: experiências, tensões, articulações e deslocamentos de uma proposta de ações afirmativas na Pós-Graduação em Minas Gerais. In:

Ações Afirmativas no Brasil: experiências 
bem-sucedidas de acesso na pós-graduação. São Paulo: Cortez: Fundação Carlos Chagas, 2016. p. 76, v. 1.

PEREIRA, Fabiana S; PORTO, Sérgio Dayrell. O Congresso silenciado: movimentos sociais, mídia e educação. In: ORTO, Sérgio Dayrell; MOTA, C. L. (Org.). Hermenêutica e análise dos discursos em jornalismo. FlorianópolisSC: Insular, 2017, v. 4, p. 178.

SIEMS-MARCONDES, Maria Edith Romano. Estudantes com deficiência no ensino superior: trajetórias escolares, acesso e acessibilidade. Inclusão Social, Brasília, DF, v. 11, n. 1, p. 94-104, jul./dez. 2017.

SOWELL, Thomas. Ação afirmativa ao redor do mundo. São Paulo, SP: Realizações, 2016.

Recebido em 02 de Junho de 2018 Aprovado em 25 de Setembro de 2019 